\title{
Veridical and nonveridical interpretations to perceived temperature differences by children and adults
}

\author{
KEVIN D. ARNOLD, GERALD A. WINER, and DELOS D. WICKENS \\ Ohio State University, Columbus, Ohio 43210
}

\begin{abstract}
This study examined responses of children and adults to a phenomenon reported initially by the philosopher John Locke: namely, that when two hands are immersed in water of a given temperature, one hand can feel warmth and the other cold. We created this effect in children and adults and compared how subjects in each age group interpreted the effect. Adults responded veridically, that is, indicating that the perceived temperature difference did not reflect a real difference in water temperature. Children, on the other hand, tended more frequently to give nonveridical responses, indicating that the felt difference signified a real difference in temperature.
\end{abstract}

Several studies have shown that illusionary changes lead children to make nonconservation-like responses. Such responses have been produced through various means, including altering the appearance of both the size of an object by means of visual illusions or distortions (e.g., Braine \& Shanks, 1965b; Murray, 1968; Tronick \& Hershenson, 1979) and the shape of an object by means of refraction in water (Braine \& Shanks, 1965a). The present study seeks to extend this earlier work by using a nonvisual illusion. The illusion involves thermal sensitivity and was first mentioned by John Locke.

In his discussion of ideas, the philosopher John Locke $(1690 / 1974)$ observed that when both hands are simultaneously immersed in water of homogeneous temperature, one hand might feel warmth and the other coolness. Weber (cited in Woodworth \& Schlosberg, 1962) claimed that if a subject initially adapted one hand in cool water and the other hand in warm water and then placed both hands simultaneously in a third pan of water of physiological zero (Nafe, 1934), the temperature at which water feels neither warm nor cool, the result was a cool sensation from the hand initially in the warm water and a warm sensation from the cooled hand. This temperature illusion will be referred to as the Locke phenomenon.

On the basis of the earlier conservation-type studies, we predicted that children and adults would respond differently to the Locke effect: Children should respond nonveridically, that is, by asserting erroneously that the perceived temperature difference was due to an actual difference in water temperature; adults should respond veridically, that is, by indicating the water was of a uniform temperature.

This study was based on Kevin Arnold's Master of Arts thesis. The research was supported by a distinguished research award grant to Delos D. Wickens, from Ohio State University.

\section{METHOD}

The sample consisted of 21 children (mean age $=6$ years 0 months) and 21 adults (mean age $=19$ years 8 months). Initially, we had each experimental subject simultaneously place the right hand in a container of cool water $\left(29^{\circ} \mathrm{C}\right)$ and the left in a container of warm water $\left(35^{\circ} \mathrm{C}\right)$ for an initial adaptation period of $75 \mathrm{sec}$. Times and/or temperatures were derived from research by Holm (1903/1962), Nafe (1934), and Weber (cited in Woodworth \& Schlosberg, 1962). Subjects were then required to place both hands in water at physiological zero $\left(32^{\circ} \mathrm{C}\right)$, and, in an attempt to determine whether the Locke effect was present, they were asked which hand was warmer. Then with both hands held above the water at physiological zero (because of rapid adaptation) subjects were asked two main questions. The first asked whether the water was "really warmer" or whether it just "felt warmer." The responses "feels warmer" and "really warmer" are veridical and nonveridical, respectively. Order of the key words in the questions was counterbalanced. For the second question, we rotated the pan $180 \mathrm{deg}$ and asked which hand would feel warmer if placed back into the water. The veridical response is the one indicating that rotating the pan should leave the warmer hand unchanged.

Of the 21 children, 14 received the aforementioned tasks. The remaining seven were asked which hand was warmer, when, with no prior temperature adaptation, both hands were placed in water at physiological zero. This question was designed to determine how children would answer the question when there was no prior temperature adaptation.

\section{RESULTS}

All 21 adults and 14 experimental children experienced the Locke illusion, indicating the "right" hand felt warmer. As a check on the responses of the children, we compared results of the 14 experimental children with the seven remaining children who were only asked to place their hands in water at physiological zero (i.e., with no prior temperature adaptation). Five of these seven children, $71 \%$, claimed that neither hand felt warmer. The clear difference between experimental and nonexperimental children underscores the strength of 
the Locke phenomenon. In summary then, both children and adults experienced the Locke effect.

On the first main test question, 6 of 13 children responded nonveridically (the water was really warmer) vs. 1 of 19 adults, a difference significant beyond the .05 level (Fisher's test, two-tailed). Subjects who responded ambiguously were not included in this or the following analysis. On the second main test question, 9 of 12 children responded nonveridically (indicating that rotating the pan would reverse the hand feeling warmer) vs. 3 of 20 adults, a difference significant beyond the .004 level. There were no effects due to sex or word order on either question.

\section{DISCUSSION}

These results show that children and adults are equally susceptible to manipulations designed to produce the Locke illusion in that initial temperature adaptation experiences led subjects in both age groups to perceive water of a uniform temperature as feeling warmer to one hand than to the other. The results indicate, however, that children and adults have markedly different interpretations of their experiences. Adults recognized the Locke effect for what it is, namely, an illusion, and they responded veridically, indicating that the water temperature was uniform. Children, on the other hand, were more frequently led astray, ostensibly by the immediacy of their perceptions, and they responded nonveridically: namely, that the perceived differences reflected real differences in water temperature.

This study, showing that a phenomenon previously created by visual illusions can be produced by an illusion that occurs in a different perceptual domain, namely, that of thermal sensitivity, emphasizes the generality of nonconservation-like behavior. Further research, involving comparisons among the Locke phenomenon, visual illusions, and other types of illusions as well, should prove beneficial in charting the breadth of nonconservative-like functioning in the life of the child. Such studies, moreover, might provide a rich source of data that are relevant for developmental theory. For instance, comparisons of conservation tasks presented in different sensory modalities might allow us to determine whether one perceptual system is more primary in the child's acquisition of conservation than another. The Locke illusion, depending upon a perceived discrepancy within the body, might also be compared to illusions that involve perceptions of discrepancies between external objects in an attempt to shed further light on the controversy (Murray, 1980) of whether conservation is first acquired with reference to the body. It is also obvious that there are a number of further studies that can be done with this illusion. It would be interesting, for instance, to test the vigor of the illusion by merely stirring the water prior to testing the child.

\section{REFERENCES}

Braine, M. D. S., \& Shanks, B. L. The conservation of a shape property and a proposal about the origin of the conservations. Canadian Journal of Psychology, 1965, 19, 197. 207. (a)

Braine, M. D. S., \& Shanks, B. L. The development of conservation of size. Journal of Verbal Learning and Verbal Behavior, 1965, 4, 227-242. (b)

Holm, K. Die Dauer der Temperaturempfindung bei constanter Reiztemperatur. In R. Woodworth \& H. Schlosberg (Eds.), Experimental psychology. New York: Holt, Rinehart \& Winston, 1962. (Reprinted from Archiv Physiologie Skandiavisch, 1903, 14, 202-258.)

LOCKE, J. An essay concerning humane understanding. New York: Meridian, 1974. (Originally published, 1690.)

Murray, F. B. Phenomenal-real discrimination and the conservation of illusion-distorted length. Canadian Journal of Psychology, 1968, 22, 114-122.

Murray, F. B. Conservation of physical attributes of animate and inanimate objects. Journal of Psychology, 1980, 104, 105110.

NAFE, J. The pressure, pain, and temperature sense. In C. Murchison (Ed.), $A$ handbook of general experimental psychology. Worcester, Mass: Clark University Press, 1934.

Tronick, E., \& Hershenson, M. Size-distance perception in preschool children. Journal of Experimental Child Psychology, 1979, 27, 166-184.

Woodworth, R., \& Schlosberg, H. Experimental psychology. New York: Holt, Rinehart \& Winston, 1962.

(Received for publication October 13, 1982.) 